\title{
EVIDENCE THAT BACILLUS PHAGE M2 IS DERIVED FROM NF BY DELETION IN A PARTICULAR REGION OF THE GENOME
}

\author{
YUKIKO MIZUKAMI AND HIDEO HIROKAWA \\ Life Science Institute, Sophia University, \\ 7-1, Kioi-cho, Chiyoda-ku, Tokyo 102, Japan
}

(Received October 21, 1985)

\begin{abstract}
It has been shown that the restriction maps of Bacillus phages M2 and $\mathrm{Nf}$ are identical to each other except in the region 32 to $46 \%$ from the left ends of the genomes. Furthermore, in this region, genomes of the original stock of phage M2 were heterogeneous in length. We have found that $\mathrm{M} 2$ has the same origin as $\mathrm{Nf}$ and that the heterogeniety in the region is caused by deletions of various sizes. These results were obtained by electoron microscopic observations of heteroduplex molecules between the genomes of $\mathrm{Nf}$ and subclones of $\mathrm{M} 2$, and by fine physical mapping of the heterologous regions. Finally, it has been shown that these deletions affected phage morphology but not multiplication.
\end{abstract}

Small Bacillus phages M2 and Nf, isolated by IKeDA et al. (1) and SHIMIZU et al. (2), respectively, are closely related to each other in many biological and physicochemical respects such as proteinase-sensitive transfection activity $(3,4)$, response to phage antiserum $(3,5)$ and their genome size (6). We have previously reported the physical maps of $\mathrm{M} 2$ and $\mathrm{Nf}$ with six kinds of restriction endonucleases (6) in which the differences in size of the restriction fragments between $\mathrm{M} 2$ and Nf were found only in a region of $32-46 \%$ from the left end of the genome ( 6 and Yoshikawa and ITo, personal communication). In the process of constructing the cleavage maps, it was found that the DNAs prepared from the M2 original stock were different in size in the same region (7). This region appeared to be in a HpaII-D fragment, since only this fragment showed a difference in size among six subclones of M2, designated H1, H2, H3, H4, H5 and H6 (7). Furthermore, one such subclone, H6, was identical to Nf in the DNA cleavage patterns of the genome with nine kinds of restriction endonucleases. These observations suggest that rearrangements of DNA, such as deletion or insertion, had occurred in a common ancestor of $\mathrm{Nf}$ and $\mathrm{M} 2$ resulting in the generation of the heterogeneity among the genomes of M2 subclones and $\mathrm{Nf}$. 
In this report, we compare five physical maps of these subclones of phages which indicate that the heterogeneous M2 population was a result of deletions of various lengths which occurred in the HpaII-D region of the Nf genome. In addition, morphological observations of these phages indicate that such deletions affect the formation of phage head projections.

\section{MATERIALS AND METHODS}

Bacterial and phage strains. Bacillus subtilis SR22 (trpC2, spo0A12) (8) was used as the host for growing bacteriophages M2 and Nf. Bacillus phage M2 (original stock) was provided by Dr. H. Saito (The Institute of Applied Microbiology, University of Tokyo) and phage Nf by Dr. J. Takagi (Department of Biology, International Christian University). $\mathrm{H} 1, \mathrm{H} 2, \mathrm{H} 3, \mathrm{H} 4, \mathrm{H} 5$ and $\mathrm{H} 6$ are subclones of M2 (original stock) isolated in our laboratory (7).

Phage and DNA preparations. The phages and their DNAs were purified by the method of ITo al et. (9). Phage DNA was digested with HpaII and the fragments were separated by electrophoresis in $1.0 \%$ agarose gel. The HpaII-D fragment was eluted from the gel as previously described by YANG et al. (10).

Cleavage maps. Cleavage maps of HpaII-D of Nf and three M2 subclones, $\mathrm{H} 3, \mathrm{H} 5$ and $\mathrm{H} 6$ were constructed by referring to the PvuII and HindIII sites in H6 and $\mathrm{Nf}$, whose locations were already known $(6,7)$. Since the other M2 subclones, $\mathrm{H} 1, \mathrm{H} 2$ and $\mathrm{H} 4$, lacked the $P v u \mathrm{II}$ site in the $H p a \mathrm{II}-\mathrm{D}$, the resulting cleavage maps of $\mathrm{H} 3, \mathrm{H} 5$ and $\mathrm{H} 6$ were referred in constructing those of $\mathrm{H} 1, \mathrm{H} 2$ and $\mathrm{H} 4$.

Electron microscopy and gel electrophoresis. Conditions for heteroduplex formation were essentially the same as described by DAVIS et al. (11). Spreading of heteroduplex molecules followed the procedure of KLEINSCHMIDT (12). Purified phages were stuck to carbon grids and negatively stained with $2 \%$ uranyl acetate. A Hitachi HS-9 at $75 \mathrm{k}$ volt electron microscope was used. Phage coat proteins were denaturated and SDS-polyacrylamide gel electrophoresed according to the methods of CARRASCOSA et al. (13).

\section{RESULTS AND DISCUSSION}

It has been shown that the physical maps of $\mathrm{M} 2$ subclones and $\mathrm{Nf}$ are identical except in the region of HpaII-D (6, Yoshikawa personal communication). This evidence was confirmed by DNA-DNA hybridization of the genomes between M2 subclones and Nf. Figure 1 shows an electron micrograph of the heteroduplex molecule between the genomes of $\mathrm{H} 1$ and Nf. A single stranded-loop was observed at the position of approximately $40 \%$ from one end of the heteroduplex DNA. This in turn, suggested that the genomes of $\mathrm{H} 1$ and $\mathrm{Nf}$ are identical except in the above region. The same observations were obtained by hybridization experiments using the DNAs of Nf and other M2 subclones (data not shown). 


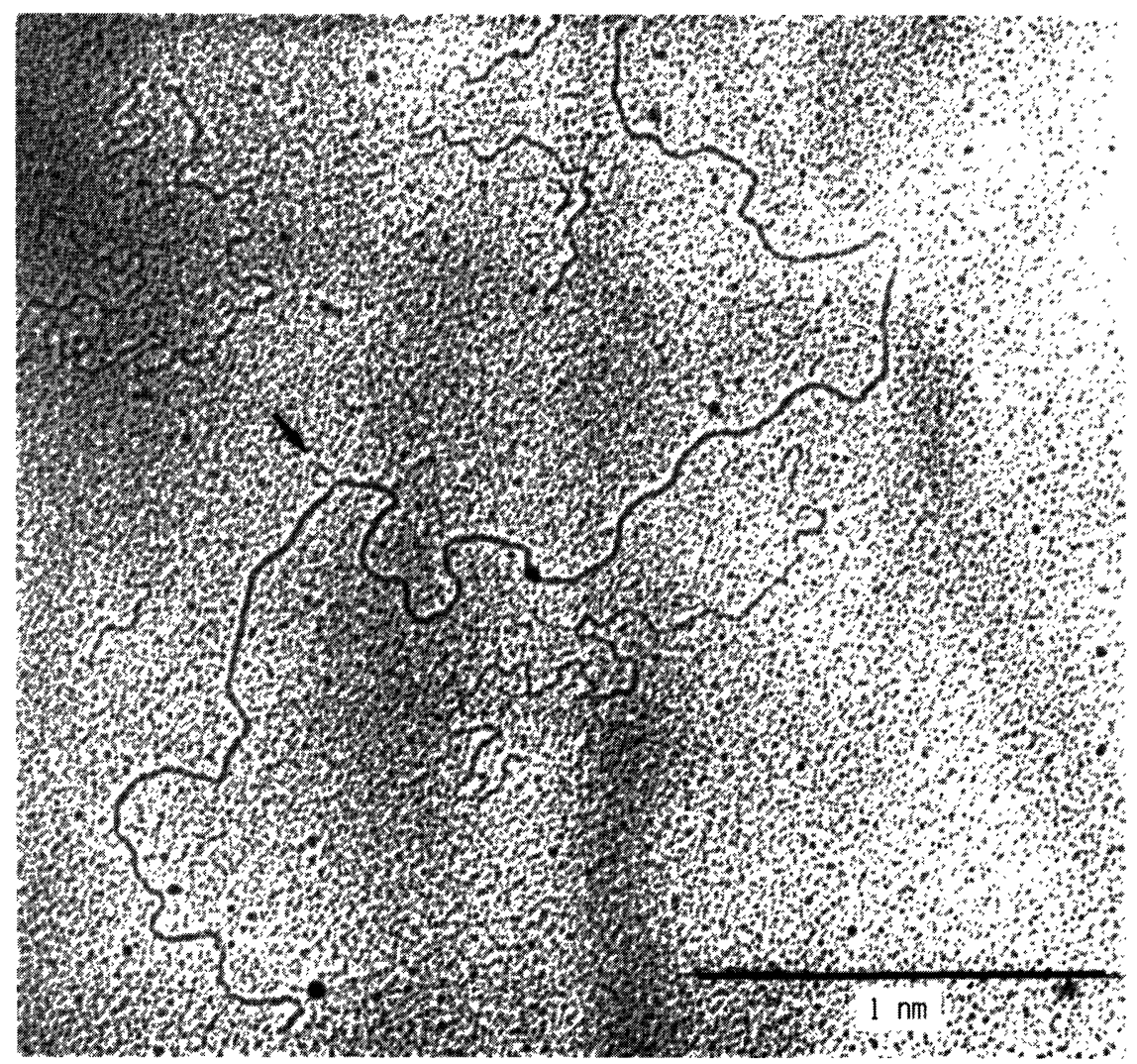

Fig. 1. Electron micrograph of the heteroduplex molecule between genomes of

$\mathrm{H} 1$ and Nf. Arrow indicates a single stranded-loop.

To determine more precisely the locations of the heterologous region of $\mathrm{Nf}$ and six subclones of M2 on their genomes, fine physical maps of the respective HpaII-D fragments were constructed using eight kinds of restriction endonucleases (Fig. 2). By a comparison of these HpaII-D fragments, the heterologous region can be further demarked within a boundary between the $H$ haI site ( $\mathrm{A}_{1}$ in Fig. 2) approximately 290 nucleotides right to the left end of HpaII-D and the DdeI site $\left(D_{5}\right)$ approximately 230 nucleotides left to the right end of the fragment. It was shown that there was no difference in $\mathrm{Nf}$ and $\mathrm{H} 6$ in the location of cleavage sites of all of the restriction enzymes tested, indicating that these two phages are identical. In $\mathrm{H} 3$, besides the conserved region as described above, the region from $D_{5}$ to $D_{4}$, which exists about 280 nucleotides further to the left of $D_{5}$, was the same as that of Nf. Similarly, the following regions were identical to those of $\mathrm{Nf}$ : in $\mathrm{H} 1$, the region from $\mathrm{A}_{1}$ to $\operatorname{Taq} \mathrm{I}$ site $\left(\mathrm{T}_{2}\right)$; in $\mathrm{H} 2$ and $\mathrm{H} 4$, from $\mathrm{A}_{1}$ to $\mathrm{D}_{2}$; in $\mathrm{H} 5$, from $\mathrm{A}_{1}$ to $\mathrm{T}_{2}$ and from $\mathrm{D}_{5}$ to $P v u$ II site $(\mathrm{P})$. These results clearly indicate, first, that M2 is derived from the origin which is identical to Nf by DNA rear- 
a.

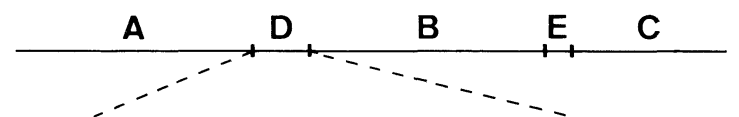

b.

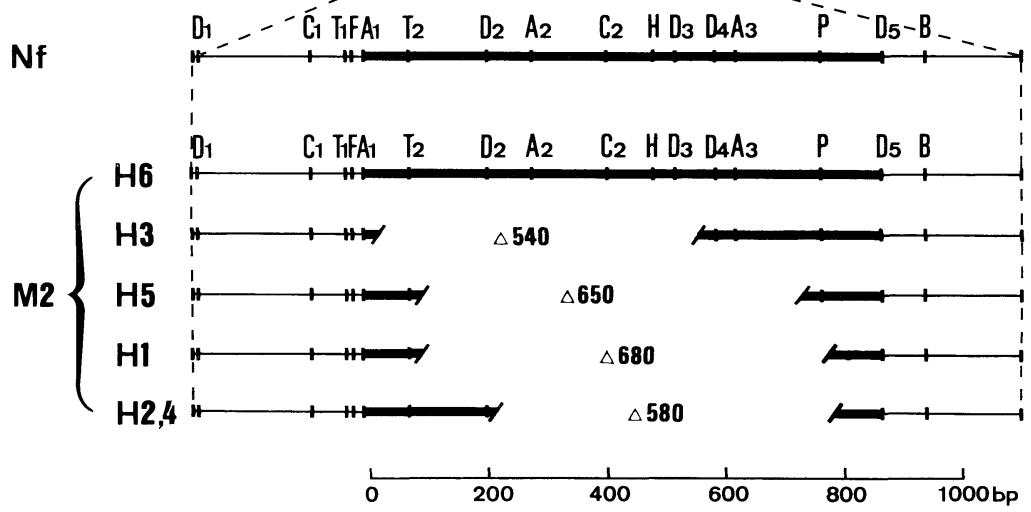

Fig. 2. Comparison of heterologous region of the M2 subclcnes and the $\mathrm{Nf}$ genomes. a. Physical map of the Nf genome with HpalI. b. Cleavage maps of HpaII$\mathrm{D}$ of the M2 subclones and Nf with restriction endonucleases. A, B, C, D, F, H, P and T represent, respectively, the sites of cleavage for HhaI, BclI, HincII, DdeI, Hinf I, HindIII, PvuII and TaqI. The solid lines indicate the region between the HhaI and DdeI sites in which the heterogeneity among M2 subclones and Nf occur. Putative endpoints of the deletions are marked with oblique lines.

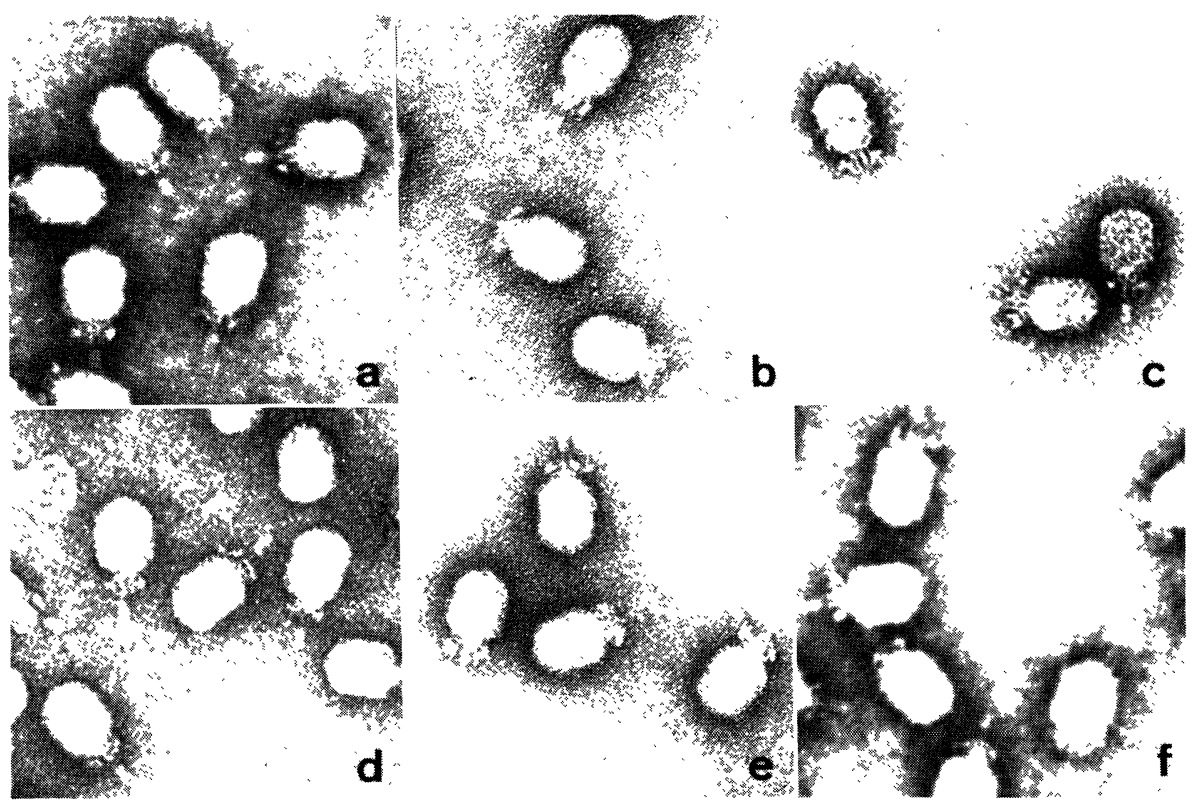

Fig. 3. The morphological differences among $\mathrm{Nf}$ and subclones of $\mathrm{M} 2$. Electron micrographs of phage particles of $\mathrm{M} 2$ subclones and $\mathrm{Nf}$ negatively stained with $2 \%$ uranyl acetate. a, Nf; b, H1; c, H2; d, H3; e, H5 and f, H6. 
a b $\quad c \quad d \quad$ e $\quad f$

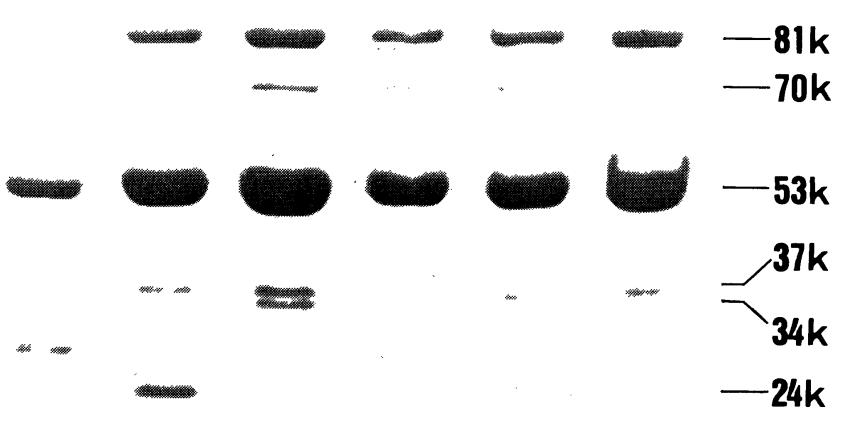

Fig. 4. SDS-polyacrylamide gel electrophoresis of phage coat proteins. The left side slot (lane a) contained $\phi 29$ coat proteins as the marker of the molecular weights which are $80 \mathrm{k}, 71 \mathrm{k}, 54 \mathrm{k}, 48 \mathrm{k}, 40 \mathrm{k}$ and $28 \mathrm{k}$ corresponding to the proteins of the neck appendage, tail, head major, upper collar, lower collar and head projection, respectively (13). Lane b, Nf; lane c, H3; lane d, H2; lane e, H5 and lane f, H1.

rangement. And second, diverse deletions which have different endpoints and lengths rather than insertions, have occurred on the boundary of the HpaII-D of the origin in the DNA rearrangement.

Since the rearrangement of the genome will cause phenotypical changes, general biological characters, such as multiplication and morphology of phages, were investigated in $\mathrm{Nf}$ and the deleted subclones of M2. Although no difference in efficiency of adsorption to the host cells, lytic profile, final yield and burst size of progeny was found among these phages, morphological alteration was observed by electron microscopy (Fig. 3). It appeared that $\mathrm{Nf}$ has fiber projections on its head (2), but not the M2 subclones, except H6. This morphological difference between $\mathrm{Nf}$ and the deleted M2 subclones was substantially confirmed by electrophoretic analysis of the phage coat proteins. Six bands of polypeptide with molecular weights of $81 \mathrm{k}, 70 \mathrm{k}, 53 \mathrm{k}, 37 \mathrm{k}, 34 \mathrm{k}$ and $24 \mathrm{k}$ were revealed by SDSpolyacrylamide gel electrophoresis of heat denatured phage virions of Nf (Fig. 4, lane b). In the deleted M2 subclones, however, only five of the polypeptides were found, or the $24 \mathrm{k}$ dalton polypeptide was not detected (Fig. 4, lanes c, d, e and f). A similar electrophoretic pattern was observed in M2Y, the other subclone of the M2 original stock (Yoshikawa and Ito, personal communication). These results indicate that the deletion of the nucleotide sequence of the $\mathrm{Nf}$ genome is concerned with a morphological alteration of the phage; in other words the protein of the head projection, or alternatively some other polypeptide(s) necessary 
for morphogenesis of the head projection, was lacking.

We are grateful for the advice of Dr. Thomas A. Trautner and appreciate the helpful discussion with Drs. Touru Mizukami, Kouji Matsumoto and Hirofumi Yoshikawa. We also thank Miss Satoko Hirokawa for a critical reading of the manuscript. This investigation has been aided by the Naito Foundation Research Grant for 1984 and by the Science Research Promotion Fund from Japan Private Foundation for 1984.

\section{REFERENCES}

1) Y. Ikeda, H. Saito, J. Takagi, and H. Aoki, J. Gen. Appl. Microbiol., 11, 181 (1965).

2) N. Shimizu, K. Miura, and H. Aoki, J. Biochem., 68, 277 (1970).

3) H. Hirokawa, J. Takagi, T. Shibata, and T. Ando, In Modern Trends in Bacterial Transformation and Transfection, ed. by A. Poltolés, B. LóPES, and M. EsPinosA, Elsevier/North Holland Biochemical Press, Amsterdam (1977), p. 3.

4) F. KaWAmura and J. Ito, Virology, 83, 233 (1977).

5) J. Takagi and H. Hirokawa, J. Gen. Appl. Microbiol., 25, 315 (1979).

6) K. Matsumoto, M. Hiruta, Y. Mizukami, and H. Hirokawa, J. Gen. Appl. Microbiol., 27, 353 (1981).

7) H. Hirokawa, K. Matsumoto, T. Minezaki, M. Hiruta, and Y. Mizukami, In Microbiology-1982, ed. by D. SCHLESSINGER, American Society for Microbiology, Washington, D. C. (1982), p. 75.

8) J. A. Hoch and J. L. Mathews, Genetics, 73, 215 (1973).

9) J. Ito, F. KaWAmura, and S. YANOFSKy, Virology, 70, 37 (1976).

10) R. C.-A. YANG, J. Lis, and R. Wu, In Methods in Enzymology, Vol. 68, ed. by R. Wu, Academic Press, New York (1978), p. 176.

11) R. W. Davis, M. Simon, and N. Davidson, In Methods in Enzymology, Vol. 21, ed. by L. Grossman, and K. Moldave, Academic Press, New York (1971), p. 413.

12) A. K. Kleinshmidt, In Methods in Enzymology, Vol. 12B, ed. by S. P. Colowick and N. O. Kaplan, Academic Press, New York (1968), p. 316.

13) J. L. Carrascosa, E. Méndez, J. Corral, V. Rubio, G. Ramírez, M. Salas, and E. VIÑUELA, Virology, 111, 401 (1981). 